\title{
Towards a Taxonomy of Virtual Work
}

\author{
Kaire Holts
}

Hertfordshire Business School Working Paper (2013)

The Working Paper Series is intended for rapid dissemination of research results, work-in-progress, and innovative teaching methods, at the pre-publication stage. Comments are welcomed and should be addressed to the individual author(s). It should be noted that papers in this series are often provisional and comments and/or citations should take account of this.

Hertfordshire Business School Working Papers are freely downloadable from https://uhra.herts.ac.uk/dspace/handle/2299/5549 and also from the British Library: www.mbsportal.bl.uk

Copyright and all rights therein are retained by the authors. All persons copying this information are expected to adhere to the terms and conditions invoked by each author's copyright. These works may not be re-posted without the explicit permission of the copyright holders.

The University of Hertfordshire is the UK's leading business-facing university and an exemplar in the sector. It is one of the region's largest employers with over 2,650 staff and a turnover of almost $£ 233$ million. It ranks in the top 4\% of all universities in the world according to the Times Higher Education World Rankings and is also one of the top 100 universities in the world under 50 years old. In the last UK Research Assessment Exercise it was given the highest rank for research quality among the post-1992 universities. 


\title{
Towards a Taxonomy of Virtual Work
}

Presented at the $31^{\text {st }}$ International Labour Process Conference 2013

Rutgers University, New Brunswick, New York, USA

\author{
Kaire Holts \\ PhD Candidate \\ Hertfordshire Business School \\ University of Hertfordshire \\ De Havilland Campus \\ Hatfield, Herts, AL10 9AB \\ United Kingdom
}

Corresponding Author: Kaire Holts (‥holts@herts.ac.uk)

Please do not quote from this paper without the permission of the Corresponding Author 


\begin{abstract}
Online spaces have led to novel forms of activity. These include real-money trading in massively multiplayer online role-playing games, on-line content production, working through crowdsourcing Internet marketplaces, online gambling, playing human-based computation games, or just browsing on the Internet, sharing files, and connecting with friends. A growing number of scholars refer to them as new labour activities, virtual work, digital labour or describe them as new sources of value creation for capital. Along with all these developments, new terms describing the virtual workforce are also emerging Gold Farmer, Prosumer, Turker or Microworker are only a few examples. Despite these new terms and categories, there is a lack of conceptual framework and understanding of what constitutes virtual work in more general terms. There is no clear classification of this type of work and no clear separation from the work that takes place in the 'real world'. This paper explores the obstacles that are blocking the way for building a classification and moving towards a definition and taxonomy.
\end{abstract}

\title{
1 Introduction
}

Discussions around new value creation or business models on the Internet are filling the pages of academic journals. Although the landscape of online value creation models is rich in variety, it is also increasingly opaque. This is partly because the research has not been able to keep up with this rapid development. In particular the understanding of the sources of value remains nebulous. The existing analyses show, however, that although virtual in their nature, online spaces and online business models continue to draw on real world work whether paid or unpaid. The objective of this paper is to create a better understanding of these forms of work that have emerged alongside the development of the Internet and commercialization of online spaces and that a growing number of scholars describe as virtual work, digital labour or new sources of value creation for capital. The topic matters because the number of people involved in virtual value creating activities is growing and new terms like for instance Gold Farmer, Prosumer, Turker, Click or Microworker are emerging. However, other than these labels, some empirical data, media interest and insular academic discussions, there is no understanding of what constitutes virtual work in more general terms - a definition and classification are missing. The first section will, therefore, discuss the emerging debates around activities that could be classified as virtual work by looking at their underlying value creation logics and in particular at the ones that draw on human labour as a source of value. It will examine the line between the real and virtual world work, look for the origin of 
the latter and try to identify communalities and differences between different forms of virtual work.

This paper seeks to shed some light on the complex landscape of virtual work by highlighting the obstacles and opacities that complicate the classification of its different forms. According to Bailey (1994), the classification of objects in the form of taxonomy reduces complexity and advances the understanding of different domains. A solid taxonomy would, therefore, provide a starting point for understanding virtual work and pave the way for a possible definition across the disciplines. However, a good taxonomy must be built on key characteristics or dimensions that need to "be both exhaustive and mutually exclusive" (Bailey (1994:3). The second and last section will, therefore, discuss the challenges and barriers when trying to identify such characteristics for the study of virtual work.

\section{Value creation techniques: continuation of old patterns or new forms?}

The literature about value creation mechanisms on the Internet is mainly spread between management studies that reflect on new business models (see e.g. Evans and Wurster, 1999; Hagel and Armstrong, 1997; Amit and Zott, 2001; Zott, et al., 2011), computer science that discusses new technological solutions (see e.g. von Ahn, 2009; von Ahn, 2008; Lechner and Hummel, 2002), and between critical voices predominantly from social sciences or critical communication and media studies (see e.g. Fuch 2011a; Terranova, 2013; Scholz, 2010). This section aims at reflecting on those value creation mechanisms that draw on human labour. It is outside the scope of this paper to address all the possible forms of virtual work separately but some examples will be explained in more detail. The focus will be on value extracting methods based on virtual communities, worklike activities in or around computer games and on crowdsourcing. These examples have been selected because of an emerging body of research and debates around them. The following analysis will look at the origin of these value creation forms and at emerging patterns and communalities between them but will, by no means, provide a full account.

\subsection{Value extracting methods based on virtual communities}

Value creation based on virtual communities gained visibility with the rise of Facebook. In the first decade of the Internet lifetime or when the gift economy ${ }^{1}$ still played a significant role, the first attempts associated with the commercialization of the Web were based on e-commerce or on selling packaged software with web browsers and web servers being the commodities (O'Reilly, 2007). Only a few corporate players saw the Internet as their sole source of wealth. The majority was skeptical about its profitability. This is also reflected in the questions that business people asked around the turn of the millennium:

\footnotetext{
${ }^{1}$ Voluntary contributions of programmers to the development of open software are a good example of a 'gift economy' that was widespread in the first decade of the Internet.
} 
"Why are profits scarce or nonexistent? Why is there so much uncertainty about Internet business models? When will some modicum of order emerge from the chaos of doing business on the Web?" (Rayport, 1999). However, since the bursting of the dot-com bubble in the autumn of 2001 the dynamics of the market have changed (O'Reilly, 2007: 17). Web applications that are delivered as a service have grown in popularity, "with customers paying, directly or indirectly, for the use of that service"(O'Reilly, 2007: 20). According to O'Reilly (2007) value has moved to services delivered over the platform and commodity has become more of a "process than a finished product" (Terranova, 2013: 47). Amazon.com was one of the first and Google and Facebook are the most prominent examples of this type of service providers that have simultaneously been shaping the Web 2.0 movement.

Many scholars argue that the creation of economic value on a platform that supports social networking, community building, file sharing, information production or blogging is generated based on social bonds, the content the participants bring into the community and users interaction like sharing files, linking, posting and commenting (Fuchs, 2011, Scholz, 2010). In 1997, Hagel and Armstrong (1997:45) predicted that advertising and transaction commission revenues would become viable sources of revenue for virtual community companies. More than ten years later, the majority of such platforms are, indeed, accumulating capital by advertising, targeted-advertising and by selling special services to their users (Fuchs, 2011: 211). The principle of these business models is that the more users participate, the more wealth is created. Without user interaction, no profit could be made because the platforms interact as service providers between a great number of actors.

However, if value is created based on users, can they be regarded as unpaid workers then? What role does labour play in these discussions? What is the connection to virtual work and how is it theorized? There is a growing body of academic literature that understands online virtual communities that are gathered on a corporate platform as a form of value creating labour (see e.g. Fuchs, 2011; Terranova, 2013; Scholz, 2010). The debate is predominantly situated in the critical media and communication studies and draws on the 'audience commodity' by Dallas Smythe and on Marx's analysis of capitalism (in particular on the creation of surplus value by capital). The underlying assumption is that user activities create surplus value and profit and the users should, therefore, be regarded as workers. For instance, Scholz explains how user activities on Facebook create surplus value and constitute, therefore, labour: "All of our actions produce value for Facebook and other companies (third parties)". Scholz (2010: 242) summarises this view by saying that "labour markets have shifted to places where labour does not look like labour at all". Targeted advertising on online platforms is often compared with the 'audience commodity' by Smythe who suggested that the mass media audience is a commodity and should be understood as a form of labour (Smythe 2006: 230). Advertisers are interested in buying the attention given to programmes that feature advertising breaks (Fuchs, 2012: 704). Similarly, according to this view, users who interact with each other or create content, constitute an audience commodity that is sold to advertisers and are, therefore, doing unpaid work. However, Fuchs (2012: 710) explains how the online value creation differs from 
traditional media because a) targeted online advertising is more efficient (more surplus value is generated in the same time period), b) users are also producers of content that is sold to advertisers: "The users' data - information about their uploaded data, social networks, their interests, demographic data, their browsing and interaction behaviour - is sold to the advertisers as a commodity" (Fuchs, 2012: 704).

Contrary to this view, Huws (forthcoming) argues that online social networking and search engine companies generate value in the form of rent and that their value does not derive from people who use the sites but from people who produce the commodities that are advertised on these platforms. As this is the case, the users cannot be regarded as workers (at least not in the form as suggested by Fuchs, 2011; Terranova, 2013 and Scholz, 2010) and value creation based on virtual communities does not belong to the debate about virtual work. Arvidsson and Colleoni (2012) challenge the debate by adding the financial rent through investments as an additional source of value for social media platforms. They suggest that the realization of value needs "to be understood as part of an extended, society-wide process of finance-centered accumulation" (Arvidsson and Colleoni, 2012). The table 1 summarizes possible revenue forms for social networking platforms mapped with corresponding user activities.

\section{Type of revenue}

Advertising, targeted advertising

Fees e.g. subscription fees, transaction fees, user fees, fees for special services or for content delivery

Sale of user data to third parties

Volunteer work e.g. translating

Facebook in other languages

Financial rent through investments

\section{User activities}

Donating unpaid services and volunteer work, sharing files, uploading photos and images, linking, posting and commenting, accumulating friends, clicking on "like" buttons (user affect), browsing, searching...

Table 1: Type of revenues and user activities that are being discussed as a possible source of value for companies using the virtual community model

When it comes to finding parallels to activities in pre-digital age then Huws (forthcoming) compares rent as a source of value with billboards and street markets where the rent for a stall-space was dependent on the location and the number (and quality) of people passing by. The richer the clientele, the higher are the stall prices. Labour that produces the commodities sold on those markets is the primary source of value creation and not the number or activities of people passing by (Ibid). Ross finds parallels between free online blogging and print media in the eighteenth century (Ross, 2013: 15) and concludes that the new forms of digital labour are based on old patterns that go back to early stages of industrialisation (Ross, 2013: 30). He states that the forms of free labour have always existed but with digital technology there are better ways to harvest them (Ross, 2013). Hagel and Armstrong (1997: 46) also mention the sale or 'rental' of member usage or transaction profiles to third parties and link this revenue 
stream to traditional businesses such as the sale of magazine subscriber lists or direct mail customer lists.

The conclusion that can be drawn is that the form of value creation on a platform that supports social networking, community building, file-sharing, information production or blogging is not unique. There are parallels to be found to television, radio, newspapers, magazines, billboards, and street markets. It can, therefore, be seen as continuation of old patterns. However, whether the users of these platforms can be regarded as virtual workers, or whether this form of value creation constitutes virtual work, remains a moot point.

\subsection{Work-like activities in or around computer games}

Work-like activities that are carried out in or around computer games or on online gambling websites (that are digital in their nature) illustrate well the contradictions and dynamics of the digital labour market as highlighted in the introduction. They are developing fast, have a changing character, provide income for millions of people but also exist in unpaid form and challenge the current understanding of what is work and what is play. There is no established body of literature that would address all the different forms of game-related work together. Game labour comes in various forms including e.g. people who work in the gaming industry like game developers (De Peuter and DyerWitheford, 2005), players who are involved in (mostly unpaid) game modification ('modding') or game testing (Küklich, 2005), the production of virtual goods and services, the real-money trading or gold farming in massively multiplayer online role- playing games (MMORPG) (Heeks, 2008), playing human-based computation games ('games with a purpose') that make people work for free (Von Ahn, 2005) or people involved in online poker or other types of online gambling (Fiedler and Wilcke, 2011). Understanding their underlying value creation forms is not straightforward due to their diverse character. Another question that arises is whether the aspect of 'game' or 'play' that they have in common is enough to address them as one category.

Academics who have analysed the playful character of work carried out in or around computer games, have suggested terms like 'playbour' (Küklich, 2005), 'ludocapitalism' (Dibbell 2006) or 'productive play' (Sotamaa, 2007) to describe the emerging forms of labour. Küklich (2005) studied user-produced game modification (modding) and suggested that "the relationship between work and play is changing, leading [...] to a hybrid form of 'playbour' " (Küklich, 2005). He compares modding with freelance work, voluntary work and with productive forms of waged labour and concludes that it has similarities with each of them. Julian Dibbell applied a similar concept to third-party gaming services in MMORPGs, calling the underlying phenomenon 'ludocapitalism' (Dibbell, 1999: 297; Dibbell, 2006: 299). Finally, Sotamaa (2007) shows how the computer game industry is dependent on playful-productive activities of their gamers. Although these analyses can serve as a good basis for categorizing all the game-related activities, it is not clear whether they would also help understanding the underlying value creation mechanisms. 
Also the question about the origin of the labour in and around computer games is difficult to answer. In their book about computer game industry, Kline, DyerWitheford and De Peuter explain that video and online gaming did not fall from the sky but "emerged on the basis of [the very] mass-mediated markets and culture" (Kline, Dyer-Witheford and de Peuter, 2003: 18). They add that online gaming has its origin in television and is the outcome of commodified entertainment culture, being thus an ideal type of commodity for post-Fordism (Kline, Dyer-Witheford and de Peuter, 2003: 75). Other authors confirm that commodification of play is the origin of most forms of online gaming (Sotamaa, 2007; Kücklich, 2005). However, this may explain the demand for game developers but does not explain the emergence of gold farming or the reasons why online poker provides income to a growing number of people. Perhaps there is no simple answer to the question regarding the underlying value creation logic of game labour. Perhaps online gaming is, indeed, an ideal type of commodity for post-Fordism and has created a number of very different value creating models. It is possible that neither the aspect of play nor the commodification of play is sufficient to capture this diversity and that each form of labour that has its origin in online games needs to be analysed separately.

One of the most controversial game-related labour activities is the real-world sale of virtual goods and services, also called gold farming, that has emerged from virtual gaming worlds. The most prominent example includes the realmoney trading that takes place in World of Warcraft ${ }^{2}$. It describes the real-world sale of virtual goods and services produced in the game. According to Heeks (2008), real-money trading in virtual worlds was first mentioned 1987 but it only took off at the beginning of the Millennium. Since then the term 'gold farming' has been in use. The gross revenue of gold farming services industry was estimated at around $\$ 1-3$ billion $^{3}$ in 2009, providing primary income to more than 100,000 workers (Heeks, 2008, Lehdonvirta and Ernkvist, 2011). More up to date statistics are missing. In gold farming, value is mostly generated by the simple act of trade of virtual goods and services. It may generate income for various agents alongside the value chain such as gamers, intermediaries and the gaming company. Table 3 summarizes the value generating activities of gold farming. When drawing parallels to activities in the real world then the World of Warcraft has, for instance, similarities with the live action role-playing game in the real life. However, the latter is not known for creating economic value on a similar scale.

\footnotetext{
${ }^{2}$ World of Warcraft (WoW) is a massively multiplayer online role-playing game by Blizzard Entertainment.

${ }^{3}$ The authors have based their estimations on aggregation of different sources
} 
Type of revenues

Players and intermediaries: Producing and selling in-game (virtual) items or services to other gamers through an intermediary or directly

Gaming company: subscription fees, fees for special services

Intermediaries: buying and selling existing virtual items
Gamer activities

Playing, farming gold, collecting ingame items (e.g. epic, legendary items in the World of Warcraft), powerleveling avatars, looking for profitable coding bugs in the game...

\section{Table 2: Value creating activities of gold farming}

Articles about the production of virtual goods and services often point out the newness of this form of labour. Wang (2006) and Heeks (2008) show that there are some elements that are new or different, such as anonymity in gameplay, trading, and the impacts of information failures and value-chain intermediaries, but otherwise the "whole activity of gold farming replicates real-world patterns of capitalist development: the commoditisation and division of labour seen for thousands of years, and the globalisation and offshoring seen for tens if not hundreds of years" (Heeks, 2008: 62). According to Wang, "Virtual gaming economies embody and reproduce real patterns of capitalist structures of labor, including alienated labor, commodity fetishism and a modern concept of labor theory of value." (Wang, 2006: 1). Wang (Ibid) goes even further and argues that the economy of virtual gaming does not produce new relations of labour, as Hardt and Negri (2000) claim, but reproduces the inequitable exploitive relations of a material capitalistic economy. "This is the key factor that is ignored in scholars who claim virtual economies have new relations in production" (Wang, 2006: 5). However Wang (Ibid) and Heeks (2008) do not elaborate their analysis. In general, there is a big gap in research and lack of reliable data about gold farmers.

Online gambling is another form of value creation that has grown rapidly in recent years. Fiedler and Wilcke estimate that there are more than 6 million online poker players in the world and more than 1.4 million people play the game for real money (Fiedler and Wilcke, 2011). Fiedler and Wilcke also study the literature about poker and conclude that most of the studies are concerned with understanding playing strategy and with the question whether poker is a game of a skill or a game of chance (Ibid). However, there is lack of research about the value creation mechanisms of online poker and about its global value chains. According to his research only in 2010 the online poker operators received 3.60 billion USD from their subscribed player community. This shows that there is a large value creation market that has not been sufficiently studied. The existing studies focus on traditional poker playing that exclude the online version of it. For instance, Bjerg studied traditional poker and came to the conclusion that poker "simulates characteristic features of capitalism and reproduces these in an accelerated and sublimated form" (Bjerg, 2011: 463). He applies Marx's framework of value creation to a game of poker and argues that poker does not create use-value since no labour goes into the game of poker. But 
what about addiction to the game that is widespread (Holts, 2013) - does it not constitute use-value in Marxist sense? According to Bjerg, "Winning in poker is a matter of the player mastering the 'market mechanisms' of the game and negotiating the 'exchange-value' of the hands in a way that redistributes the value at stake in the game at his benefit" (Bjerg, 2011: 455). This and other questions need a more detailed analysis, in particular looking at online poker as a possible form of work.

In addition to game activities that generate income for players, there are also forms of unpaid game activities that create value for the game industry or other businesses. 'Modding' or computer game modification and human-based computation games ('games with a purpose'4) are two popular examples for this. Küklich (2005) studied 'modding' as a value generating activity and concluded that this and "other similar forms of 'free labour' do not fit the categories of wage labour, freelance or voluntary work, and neither do they fit the categories of leisure, play or art. While free labour, or "playbour", shares traits with all of these occupational types, it can only be understood on its own terms" (Ibid). Value generation based on human-based computation games will be explained in the following section.

It can be concluded that work-like activities that are carried out in or around computer games or on online gambling websites are based on different types of value generating mechanisms. However, they are partly overlapping with value creation logics based on virtual communities and crowdsourcing. Similarly to other forms of virtual work, there is a big gap in research and lack of empirical data.

\subsection{Crowdsourcing}

Another value creation model that has emerged on the Internet and that draws heavily on human labour as a source of value is web-based crowdsourcing. This term refers to outsourcing of tasks that were traditionally performed by employees or contractors. Generally this is done in the form of an open call addressing an undefined but large group of people (Howe, 2009). The difference from outsourcing is that crowdsourcing relies on individuals while outsourcing draws on other companies and employees. It is also described as a distributed problem-solving production model (Brabham, 2008: 76) or as "a sourcing model in which organizations use predominantly advanced Internet technologies to harness the efforts of a virtual crowd to perform specific organizational tasks" (Saxtona et al., 2013: 6). Corney describes crowdsourcing as "a tool to enable open innovation in firms that look to advance their technology or improve their products using external contributors" (Corney et al., 2009). Although these definitions have emerged recently, several authors show that the idea of crowdsourcing is not new and that it goes back to non-profit collaborative online communities in the digital age and to open call contests in the pre-digital age (see e.g. Geiger et al., 2011:1; Corney et al., 2009; Thomas, 2011). Napoleon used

\footnotetext{
${ }^{4}$ For instance the ESP Game
} 
the power of the crowd as early as the $19^{\text {th }}$ century when looking for innovative ideas for preserving large amounts of food and for a substitute for butter. As a result canned food and margarine were invented (Thomas, 2011). The Oxford English Dictionary used the power of hundreds of volunteers to improve its consistency (Ibid). These and many more examples show that the idea of using the power of the crowd to perform large-scale tasks or to find innovative solutions to certain problems is extremely old. However, none of these examples reached the scale and efficiency of web-based crowdsourcing projects. What has changed is the rise of for-profit crowdsourcing and with it the emergence of crowd workers who rely on it as the only source of income (see e.g. studies by Caraway, 2010: 120; Ross et al., 2010; Ipeirotis, 2010a). Digital technologies have made it easier to recruit workers, to channel and sell the results of the crowd (Corney et al., 2009). The community's creation has become business and the activities of the crowd a source of profit. It can be said that similarly to Ross' statement about free labour (Ross, 2013), crowdsourcing has also always existed but with digital technology it is easier to harvest it.

But what are the characteristics of this type of work and how does it compare to other forms of virtual work? One of the characteristics of crowdsourcing is the dissolution of conventional employer-employee relationships that is replaced by more casual and short-lived forms of collaboration focusing on tasks or collaborative processes or by unpaid game activities. In terms of activities, it typically includes working through crowdsourcing Internet marketplaces, playing human-based computation games or participating in other computational processes whether consciously or not.

The existing literature points at several movements and technological advances that have paved the way for value creation based on collaborative processes and on the knowledge of the crowd. These include open source production (Malone and Laubacher, 1998: 146), human computation (Geiger et al., 2011) and the Web 2.0 movement (O'Reilly, 2007). From a technical point of view, web-based crowdsourcing platforms and computer algorithms have been the main engines (Saxtona et al., 2013: 9) behind the transformation of ordinary web users into virtual crowd workers or as Quinn and Bederson (2011) wrote: "organizing web users to do great things". As noted in the introduction, crowdsourcing perfectly reflects the diversity and characteristics that are typical of virtual work like the fusion of work and play, intertwining of work and leisure time and dissolution of formal employment relationships. A crowd worker can be both paid and unpaid, conscious about their contribution to value creation or not, embedded in a gamelike environment or not, paid by real or virtual money (see e.g. Saxtona et al., 2013). What is common to all these different forms of crowdsourcing is that they are channeled through the web and mostly through online service platforms that give companies access to the global pool of workers, serve as intermediaries in the value chain and play a key role in the rapid growth of crowdsourcing. The undefined crowd or the large network of workers, the crowdsourcing service platforms and the corporate sector are, therefore, the main agents in the value creation. As stated above, not all the participating individuals receive a monetary compensation, although the whole value creation process relies on human labour (Brabham, 2008: 83). In contrast, the requesters of crowdsourcing services profit in the form of commodity sale or the improvement of internal production 
processes (see table 3). The crowdsourcing service platforms use different value creation models ranging from subscription fees to third-party advertisement. To make them even more complicated to understand, it is not only the distribution of wealth that varies but also the types of tasks that are outsourced.

\section{Type of revenue / requesters of crowdsourcing services}

\begin{tabular}{|c|c|}
\hline $\begin{array}{l}\text { Sale of goods and services produced by } \\
\text { the crowd (e.g. through micro-tasks, } \\
\text { public design and innovation contests, } \\
\text { use of innovative ideas that improve } \\
\text { the quality of products, services and } \\
\text { internal processes) }\end{array}$ & \multirow[t]{4}{*}{$\begin{array}{l}\text { Donating unpaid services and volunteer } \\
\text { work, performing Human Intelligence } \\
\text { Tasks (HITs), participating in design } \\
\text { contests, producing goods and services, } \\
\text { playing human-based computation } \\
\text { games, solving CAPTCHAs... }\end{array}$} \\
\hline $\begin{array}{l}\text { Sale of user-generated content (e.g. } \\
\text { photographs and design) }\end{array}$ & \\
\hline $\begin{array}{l}\text { Volunteer work of the crowd e.g. } \\
\text { writing reviews on the Internet (e.g. on } \\
\text { TripAdvisor or Amazon) }\end{array}$ & \\
\hline $\begin{array}{l}\text { Type of revenue / crowdsourcing } \\
\text { online service platforms }\end{array}$ & \\
\hline \multicolumn{2}{|l|}{ Subscription fees } \\
\hline \multicolumn{2}{|l|}{ Sale of user data to third parties } \\
\hline \multicolumn{2}{|l|}{$\begin{array}{l}\text { Selling services like quality control, } \\
\text { aggregation of micro-tasks, monitoring } \\
\text { tools, payment systems }\end{array}$} \\
\hline Advertising, targeted advertising & \\
\hline
\end{tabular}

\section{Crowd activities}

Donating unpaid services and volunteer work, performing Human Intelligence Tasks (HIT), participating in design contests, producing goods and services, playing human-based computation games, solving CAPTCHAs..

Table 3: Type of revenues of crowdsourcing platforms, requesters of crowdsourcing services (businesses) and corresponding crowd activities

At one end of the spectrum there are complex problems that are broken down into small tasks, which require very little time and low skills to be completed - in some cases only the ability to click. After the completion of small tasks by a network of workers, usually for low compensation, the project is recomposed with the help of digital tools. In such projects the workers often remain anonymous and are sometimes called 'turkers', 'click' or 'microworkers' (Lehdonvirta and Ernkvist, 2011: 24; Ipeirotis, 2010a).

However, crowdsourcing can also involve outsourcing of tasks that require higher skills and creative thinking. In this case there is not a large number of people working on one problem but a company has a choice between a large distributed group of individuals. These tasks typically include writing, translation, graphic design, website and software development or day-to-day office tasks. The easy access to a large group of crowd workers who are willing to invest their time, energy and skills often eliminates the need to hire a local 
expert or an employee. As the workers can be located anywhere in the world, many national laws with their minimum wage requirements cease to have effect. The unregulated area of crowdsourcing, together with the brisk competition between individual workers from all over the world, has, therefore, lowered the level of compensation companies are willing to pay (see e.g. Quinn and Bederson, 2011; Ipeirotis, 2010b, Ross et al., 2010).

The development of crowdsourcing has not only lowered wages (see e.g. Ross et al., 2010; Schenk and Guittard, 2011) and created a new workforce but has also transformed some formerly paid jobs into unpaid activities. An example of this includes design contests with a company looking for new design ideas for its products or for innovative solutions to its business problems through an open call. Typically this type of call addresses a large number of people, promising the winner a reward in the form of mass production of their ideas instead of a monetary compensation (Brabham, 2008: 76). This business model is often praised by using phrases like "the wisdom of the crowd", "crowd" or "collective intelligence", "the innovative power of the crowd" or "distributed", "plural" or "collaborative problem" solving (see e.g. Howe, 2009; Brabham, 2008; Malone and Laubacher, 1998; Quinn and Bederson, 2011). However, the existing literature about crowdsourcing is rather reserved when it comes to analyzing the elimination of formerly paid work by designers and other experts involved in product design and similar tasks. The question to ask here is whether an outsourced task in the form of a competition still constitutes work and if so, how it should it be theorized and categorised. Is it still virtual work?

The question is even more challenging when the crowd creates value in exchange for entertainment, or when people playing computer games, without consciously doing so, simultaneously solve large-scale problems (von Ahn, 2006:96). This business model is sometimes called game with a purpose or simply 'human computation'. Although Quinn and Bederson (2011) argue that human computation is not synonymous with crowdsourcing, its value creation logic looks similar, drawing on the same type of labour. For instance the ESP Game was designed for the purpose of labeling web images and creating a database that aimed at improving the quality of web-based image search (von Ahn, 2006:96). Another innovative example is the reCAPTCHA system that asks users to enter words seen in distorted text images necessary to protect websites from computer-generated spam. By doing so, these users contribute (often not consciously) to the digitization of old books and newspapers (von Ahn et al., 2008: 1465). For instance, through the reCAPTCHA system, the entire New York Times Archive from 1851 to 1980 was digitized in less than 12 months by using the labour power of the crowd (von Ahn, 2009). The computer scientist Luis von Ahn is a pioneer of crowdsourcing models that link entertainment with computational tasks. Interestingly, on his blog he addresses the question of categorisation by referring to unpaid activities as work. He also concludes that making the crowd work for free in exchange for entertainment is legitimate:

"Assume we decide as a country that labor markets like Mechanical Turk should be legislated and a minimum wage is imposed. Some of the work on human computation involves transforming tasks into enjoyable games so that people perform them in exchange for entertainment. Is it ok to pay 
people less (or nothing) if the task is fun? What about writing a review for a book online or rating a video? These are concrete pieces of work that benefit the Web sites, but that nobody seems to object to doing for free." (von Ahn, 2010)

However, this type of conclusion requires more analysis than the current research is able to provide. There is also lack of studies focusing on workers' perspective. For instance, according to Howe, crowdsourcing uses the network to harness individual people's spare cycles - the time and energy left over after their obligations to employers and family are fulfilled (Howe, 2009: 13). Yet, the few empirical studies (see e.g. Caraway, 2010: 120; Ross et al., 2010; Ipeirotis, 2010a; Ipeirotis, 2010b) show that contrary to Howe's view, for a substantial number of crowd workers it is their primary source of income. This shows that more critical and comparative analyses of crowdsourcing are needed. There is an obvious mismatch between theory and the reality. This is partly because a substantial part of crowdsourcing literature is written by researchers from management and computer studies, often cross referencing each other. However, the lack of workers' perspective in their studies makes it difficult to find a common basis with other forms of virtual work and to move towards a taxonomy and a possible definition. There is also no clear understanding of the underlying value creation processes and how to distinguish between different forms of crowdsourcing (Geiger et al., 2011:1). It is only clear that crowdsourcing exists in paid and unpaid form relying on both skilled and unskilled workers. It has transformed paid work into unpaid activities but also unpaid work into paid work. As for motivational factors, a wide range of possible factors is listed in the literature (see e.g. Ipeirotis, 2010a; Quinn and Bederson, 2011; Geiger et al., 2011). What is also clear is that crowdsourcing blurs the boundaries between work and play and work and leisure time. It contributes to the dissolution of conventional employer-employee relationships, and to the degradation of wages and its success relies on digital technologies and the Web. However, is this a sufficient basis for asserting communalities between different forms of crowdsourcing and to distinguish them from other forms of work?

\section{Towards a taxonomy and definition of virtual work: obstacles and opacities}

The previous section gave an overview of debates about activities that can be classified as virtual work. However, there are several factors that complicate our understanding of it. There are three main problems: one is concerned with the shifting boundaries between work and play, and between consumption and production, the second with the conceptualisation of value and the third one with existing knowledge about different forms of virtual work. 


\subsection{How should the pool of different forms of virtual work be defined?}

A challenging question to ask when trying to develop a definition is how should the pool of different forms of virtual work be defined? What type of work qualifies as 'virtual work'? The biggest challenge derives from the widely discussed fusion of work and play, intertwining of work and leisure time, and the merging of consumption and production. Should an activity that is unpaid but creates monetary value for capital be considered as work? Or can paid labour that has elements of fun be seen as work? These are fashionable topics to discuss, in particular among scholars from media and communication studies (see e.g. Andrejevic, 2013; Goggin, 2011; Terranova, 2013; Kücklich, 2005; Fuchs, 2011). There is no straightforward answer to these questions but it is clear that the blurring of boundaries between different spheres complicates the understanding and the demarcation of what should be included in the category of virtual work. However, the problem is not limited to the Internet and to digital industries only.

A study by Gershuny (2000) provides empirical evidence for the shift towards leisure societies and the blurring boundary between work and leisure and thus an interesting starting point for mapping the landscape of digital work. The study brought together time-diary data from twenty industrial countries and produced a historical account of how time-allocation has changed over the last third of the twentieth century (Gershuny, 2000: 4). According to Gershuny, there is a general decline in work time and growing leisure preference: "The balance of waking time has shifted in general away from work, towards leisure." (Gershuny, 2000: 133). However, for a society as a whole, he found that the more leisure time, the more hours spent on work. This apparent paradox can be explained by the increasing number of service jobs in the 'leisure' industry (Gershuny, 2000: 134). The questions to ask with respect to work in online spaces are the following: if the shift from work towards more leisure (or simply because there is less paid work available) creates new jobs then what exactly are these digital jobs that the 'leisurely' world wide web and digital technologies have created? Are we able to recognise them? To what extent are these jobs based on alternative or new value creation models? This leads to the question whether we can distinguish between leisure activities and unpaid work? How many of the activities that are considered as fun or free time activities like e.g. browsing on the web, using Facebook fall in reality into the category of unpaid work and are hidden from statistics? Although Gershuny did not look separately at computerrelated activities, he pointed out that an adequate distinction between unpaid work and leisure is increasingly difficult. (Gershuny, 2000: pp. 108-109).

One could also ask what triggers the shift towards a leisure society and the convergences mentioned above? There are different opinions. While Terranova suggests that the merging of consumption and production is symptomatic of post-Fordism (Terranova, 2013: 37), Kücklich argues that the fusion of play and work is a result 'of 'a deregulation' of work in which the primary source of coercion is no longer the institution an individual works for, but the individual herself" (Kücklich, 2005). At the same time Goggin (2011) analyses the convergence culture we live in and concludes that history does not provide enough evidence that would allow us to see play and work as two different 
spheres. In fact, the boundary has always been blurry. Spencer (2009) concludes with a similar statement: "The distinction between work and leisure is, in reality, an artificial one" (Spencer, 2009: 140). However, in order to understand all the possible reasons for the convergence requires a clearer distinction between play and work, consumption and production debates but this is outside the scope of this paper.

Based on the discussion about the shifting boundaries, it can be concluded that different forms of virtual work are not necessarily to be found in the category of paid work and that we should look beyond it. Or as long as these questions are not clear we should not distinguish between paid, unpaid and leisure activities in virtual spaces but should focus on underlying value creation mechanisms. It does not happen accidentally that human activities create economic value. Whether a person is paid or not, formally employed or not, or whether there is a creation of monetary value out of his or her activity usually follows certain logics and is based on a business model. On the Internet, businesses have been particularly successful in putting forward value creation mechanisms that draw on human labour without engaging in formal employment relationships.

\subsection{Confusion around the concept of value}

The second problem is concerned with the confusion around the concept of value. It is similar to the problem related to the shifting boundaries between work and play but has a slightly different angle. According to Gorz (1994: 54), work only becomes work if it generates value that can be exchanged on the market. This goes back to the value creation debate that was first theorised by classical economists including Adam Smith, David Ricardo, and Karl Marx. The classical economists were the first to recognise the importance of labour as the source of value, necessary for capital accumulation (Spencer, 2009). For this reason, understanding the value creation logic that involves labour is important for understanding the nature of work. There are two aspects that need to be explored in this context. One is the way value is generated; the other includes understanding the source of value, which traditionally refers to human labour. As showed in the previous section, there is lots of confusion about understanding the sources of value and value creation mechanisms on the Internet. However, as long as there is no understanding about these value creation mechanisms, it is not clear what qualifies as virtual work. Although (sometimes for slightly different reasons) there are many authors who call for reconfiguration of the concept of value and its measurement, explaining that the traditional tools and concepts do not capture all forms of value creation (see e.g. Morini and Fumagalli, 2010; Böhm and Land, 2012). Böhm and Land criticize the labour process theory (LPT): “...as long as LPT assumes that the employment relationship is the only location of capitalist labour process, the theory might blind itself to fundamental changes that have moved labour outside of the workplace and contract-based employment" (Böhm and Land, 2012: 223). Although Morini and Fumagalli analyse affective labour, they come to a similar conclusion with regard to the labour theory of value as a tool for measuring value generation: "...the labour theory of value must dynamically adjust to the 
capitalist system and the succession of different modes of accumulation" and conclude that the labour theory of value must be rethought (Morini and Fumagalli, 2010). There are other authors whose demand is less concrete but who conclude in a similar way by calling for new theoretical frameworks (see e.g. Banks and Humphreys, 2008; Cubitt, 1998; Petersen, 2008). However, concrete suggestions for new tools and theories are rare.

\subsection{Lack of knowledge}

The third problem is that the existing knowledge about the emerging value creating activities on the Internet is far from being complete. On the one hand, there is shortage of empirical studies and the existing studies often have a narrow focus on one type of activity, investigating e.g. Gold Farming (Heeks, 2008), Crowdsourcing (Howe, 2006), Prosumption (Ritzer \& Jurgenson, 2010; Beer \& Burrows, 2010) or are addressing it on a rather abstract level describing it for instance as free (Terranova, 2013) or immaterial labour (Lazzarato 1996; Coté \& Pybus, 2010; Pybus, 2011). On the other hand, digital labour is being studied by a variety of disciplines. Each discipline, however, has a different focus and tends to ask slightly different questions. While researchers from media and communication studies are concerned with the exploitation of free labour (see e.g. Ross, 2013; Terranova, 2013), computer scientists are exploring new ways of how to use people's 'free' labour time to create value for capital (see e.g. von Ahn and Dabbish, 2008). And while mainstream economists are primarily interested in understanding the market size and the contribution of the activities in virtual environments to real world economies (Castronova, 2002), more critical voices from heterodox economics look at wealth distribution and decomposition of classes. Although there are studies that draw parallels between labour in the digital and pre-digital ages (Ross, 2013; Terranova, 2013), a cross-disciplinary analysis is missing. This makes an inventory, development of a definition and comparison of different forms of work emerging on the Internet difficult. It also makes it difficult to identify dimensions across the different forms of digital work.

Furthermore, dimensions only become valid if they are matched with possible values, ideally based on empirical data. However, as shown, the amount and quality of empirical data about virtual work is incomplete or uneven. According to Bailey (1994), a successful classification is characterized by the ability to identify the key characteristics on which the classification is to be based: "The only basic rule is that the classes formed must be both exhaustive and mutually exclusive" (Bailey, 1994: 3). What could be the possible key dimensions that would form exhaustive and mutually exclusive classes of virtual work? Traditionally, the study of work has focused on the full-time employment model and on dimensions like control over the work process, the contractual nature and the number of parties involved in the work relationship (Cappelli and Keller, 2012). However, this model has already shown its weaknesses after the growth of alternative work arrangements like independent contracting and temporary work (Ibid), and it is even more difficult to apply to virtual work. As shown in the previous section, on the Internet, businesses have been particularly successful in 
putting forward value creation mechanisms that draw on human labour without engaging in formal employment relationships thus a classification system is needed that captures this diversity.

\section{Conclusion}

The objective of this paper was to create a better understanding of the emerging value creating activities on the Internet. It focused on those models that draw on human labour and activities that are referred to as virtual work and namely on value extracting methods based on virtual communities, work-like activities in or around computer games and crowdsourcing. It has tried to search for their origin, to draw parallels with work outside of virtual spaces, identify emerging patterns and communalities between different forms of virtual work.

Based on this analysis, the paper identified the obstacles and opacities that complicate the classification of different forms of virtual work. It identified three main problem areas. First, virtual work is accompanied by the trend of shifting boundaries between work and play, intertwining of work and leisure time, and the merging of consumption and production. It was shown that different forms of virtual work are not necessarily to be found in the category of paid work but they are often outside the formal employment relationships or even among activities that look like leisure and are unpaid. However, whether all these forms of value creation constitute virtual work, is debatable. As a result, it is difficult to define what qualifies as virtual work. Second, we could see that there is a great deal of confusion around the concept of value and that the traditional concepts and tools do not capture all the forms of value creation. However, understanding the value creation logic that involves human labour is necessary for understanding the nature of work. As long as it is not clear how value is created and what are the exact sources of value, it is, again, difficult to define the pool of virtual work. Third, it was shown that the amount and quality of empirical data about virtual work is incomplete or uneven. It is studied by a variety of disciplines that look at it from different perspectives. There is lack of crossdisciplinary analyses and empirical data. This in turn hinders the identification of key dimensions necessary for a taxonomy.

As long as these obstacles are not addressed or solved, it will be challenging to move towards a better understanding of virtual work. More empirical data, investigation, inter-disciplinary research, new tools and theories or adaptation of old ones are needed before a taxonomy and a definition of virtual work can be developed. Parts of the research agenda presented in this paper will be taken forward in a doctoral thesis that is focusing on gold farming - a paid form of virtual work. It aims at applying existing theoretical frameworks such as the labour theory of value and labour process theory to gold farming in order to make sense of virtual work in a wider sense. 


\section{References}

Amit, R., \& Zott, C. (2001) 'Value creation in e-business'. Strategic Management Journal. 22. pp. 493-520.

Andrejevic, M. (2013) 'Estranged Free Labour'. In Scholz, T. (ed) (2013) Digital Labor: The Internet as Playground and Factory. London: Routledge.

Arvidsson, A. \& Elanor Colleoni, E. (2012) 'Value in Informational Capitalism and on the Internet'. The Information Society: An International Journal. Volume 28, Issue 3, 2012. pp. 135-150.

Bailey, K. D. B. (1994) Typologies and Taxonomies: An introduction to classification techniques. Sage University Paper Series on Quantitative Applications in the Social Sciences, series no. 07-102. Thousand Oaks, CA: Sage.

Banks, J. \& Humphreys, S. (2008) 'The Labour of User Co-Creators: Emergent Social Network Markets?'. Convergence: The International Journal of Research into New Media Technologies. November 2008, 14. pp. 401-418.

Beer, D. \& Burrows, R. (2010) 'Consumption, Prosumption and Participatory Web Cultures'. Journal of Consumer Culture, 10 (1) pp. 3-12.

Bjerg, 0. (2011) 'Poker phases: Draw, Stud and Hold'Em as play-forms of capitalism'. ephemera: theory \& politics in organization, volume 11, number 4 (November 2011) pp. 450-465.

Böhm, S. \& Land, C. (2012) 'The new 'hidden abode': reflections on value and labour in the new economy'. The Sociological Review. 60:2 (2012) pp. 217-240.

Brabham, D. C. (2008). 'Crowdsourcing as a Model for Problem Solving. An Introduction and Cases'. Convergence: The International Journal of Research into New Media Technologies, Vol 14(1) pp. 75-90.

Cappelli, P. \& Keller, J.R. (2012) 'Classifying Work in the New Economy'. ACAD MANAGE REV. July 24, 2012. Published ahead of print July 24, 2012. [Online] Available at: http://amr.aom.org/content/early/2012/07/20/amr.2011.0302.abstract [Accessed: 30 January, 2013].

Caraway, B. (2010) 'Online labour markets: an inquiry into oDesk providers'. Work Organisation, Labour and Globalisation, Volume 4, Number 2 / Autumn 2010. pp. 111-125.

Castronova, E. (2002) 'On Virtual Economies'. CESifo Working Paper Series No. 752, category 9: Industrial Organisation, July 2002. [Online] Available at: http://ssrn.com/abstract=338500 [Accessed: 30 January, 2013]. 
Corney, J.R., Torres-Sánchez, C., Jagadeesan, P., Lynn, A. \& Regli, W. (2009) 'Outsourcing labour to the cloud'. International Journal of Innovation and Sustainable Development. 4 (4) pp. 294 - 313.

Coté, M. \& Pybus, J. (2010) 'Learning to immaterial labour 2.0: MySpace and Social Networks'. ephemera: theory \& politics in organization, 7 (1) pp. 88-106.

Cubitt, S. (1998) Digital Aesthetics. London: Sage.

De Peuter, G. \& Dyer-Witheford, N. (2005) 'A playful multitude? Mobilising and counter-mobilising immeterial game labour'. The Fibreculture Journal, 5. [Online] Available at: http://five.fibreculturejournal.org/fcj-024-a-playful-multitudemobilising-and-counter-mobilising-immaterial-game-labour/ [Accessed: 30 January, 2013].

Dibbell, J. (2006) Play Money: Or, How I Quit My Day Job and Made Millions Trading Virtual Loot. New York: Basic Books.

Dibbell, J. (1999) My Tiny Life: Crime and Passion in a Virtual World. New York: Henry Holt, 1999.

Evans, P. \& Wurster, S. T. (1999) 'Getting Real About Virtual Commerce'. Harvard Business Review, November- December 1999. pp. 84-94.

Fiedler, I. \& Wilcke, A-C. (2011) 'The Market for Online Poker'. [Online] Available at: http://ssrn.com/abstract=1747646 [Accessed: 30 January, 2013].

Fuchs, C. (2012) 'Dallas Smythe today - the audience commodity, the digital labour debate, Marxist Political Economy and Critical Theory. Prolegomena to a digital labour theory of value'. tripleC - Journal for a Global Sustainable Information Society 10 (2) pp. 692-740.

Fuchs, C. (2011) 'The contemporary world wide web: social medium or new space of accumulation?'. In Winseck, D. \& Yong Jin, D. (eds.) The Political economies of the media: the transformation of the global media industries. London: Bloomsbury.

Geiger, D., Seedorf, S. \& Schader, M. (2011) 'Managing the Crowd: Towards a Taxonomy of Crowdsourcing Processes'. Proceedings of the Seventeenth Americas Conference on Information Systems, Detroit, Michigan August 4th-7th 2011, Paper 430. [Online] Available at: http://aisel.aisnet.org/amcis2011_submissions/430 [Accessed: 30 January, 2013].

Gershuny, J. (2000) Changing Times: Work and Leisure in Postindustrial Society. New York: Oxford University Press.

Goggin, J. (2011) 'Playbour, farming and leisure'. ephemera: theory \& politics in organization, volume 11, number 4 (November 2011) pp. 357-368. 
Gorz, A. (1994). Capitalism, Socialism, Ecology. Translated by Turner, C. London, New York: Verso.

Hagel, J. \& Armstrong, A. (1997) Net Gain: Expanding Markets Through Virtual Communities. Harvard Business School Press.

Hardt, M. \& Negri, A. (2000) Empire. London: Harvard University Press.

Heeks, R. (2008) 'Current Analysis and Future Research Agenda on "Gold Farming": Real- World Production in Developing Countries for the Virtual Economies of Online Games'. Development Informatics Group, Institute for Development Policy and Management, University of Manchester.

Holts, K. (2013) Semi-structured interviews with online poker players in Estonia. [interviews]. December 2012-January 2013.

Howe, J. (2009) Crowdsourcing: Why the Power of the Crowd Is Driving the Future of Business. London: Random House Business Books

Howe, J. (2006) 'The Rise of Crowdsourcing'. Wired Magazine, Issue 14.06, June 2006.

Huws (forthcoming) 'Living, labour and value in the 21st century: unpicking the knot'. Socialist Register 2014: The Remaking of Class.

Ipeirotis, P. (2010a) 'Demographics of Mechanical Turk'. Working Paper CeDER10-01, New York University, Stern School of Business.

Ipeirotis, P. G. (2010b). 'Analyzing the amazon mechanical turk marketplace'. XRDS: Crossroads, The ACM Magazine for Students, 17(2), 16-21.

Kline, S., Dyer-Witheford, N. \& De Peuter, G. (2003) Digital Play: The Interaction of Technology, Culture, and Marketing. McGill-Queen's University Press.

Kücklich, J. (2005) 'Precarious playbour: Modders in the digital games industry', Fibreculture, 5. [Online] Available at: http://journal.fibrec ulture.org/issue5/index.html [Accessed: 30 January, 2013].

Lazzarato, M. (1996) 'Immaterial Labour'. In Virno, P. \& Hardt, M. (eds.) Radical Thought in Italy: A Potential Politics. Minneapolis: University of Minnesota Press. pp. 132-146.

Lechner, U. \& Hummel, J. (2002) 'Business Models and System Architectures of Virtual Communities: From a Sociological Phenomenon to Peer-to-Peer Architectures'. International Journal of Electronic Commerce. Spring 2002, Vol. 6, No. 3. pp. 41-53.

Lehdonvirta, V. \& Ernkvist, M. (2011) Knowledge Map of the Virtual Economy. Washington DC: World Bank. 
Malone, W. T. \& Laubacher, J.R. (1998) 'Are big companies becoming obsolete? The Dawn of the E-Lance Economy'. Harvard Business Review, Reprint 98508, September-October 1998. pp. 145-152.

Morini, C. \& Fumagalli, A. (2010) 'Life put to work: Towards a life theory of value'. ephemera: ositheory \& politics in organization, Volume $10(3 / 4)$ pp. 234252.

O'Reilly, T. (2007) 'What is Web 2.0: Design Patterns and Business Models for the Next Generation of Software'. Communications \& Strategies, No. 1, p. 17, First Quarter 2007. pp. 17-37.

Petersen, S. M. (2008) 'Loser Generated Content: From Participation to exploitation'. First Monday, Volume 13, Number 3 - 3 March 2008. [Online] Available at:

http://firstmonday.org/htbin/cgiwrap/bin/ojs/index.php/fm/rt/printerFriendl y/2141/1948 [Accessed: 30 January, 2013].

Pybus, J. (2011) 'The Subjective Architects: When Tweens Learn to Immaterial Labor'. Journal of Communication Inquiry. 35 (4) pp. 403-409.

Quinn, A. J. \& Bederson, B. B. (2011) 'Human Computation: A Survey and Taxonomy of a Growing Field'. In Proceeding, CHI '11 Proceedings of the SIGCHI Conference on Human Factors in Computing Systems, pp. 1403-1412.

Rayport, J. (1999) 'The truth about Internet Business Models'. Strategy and Business (1999) pp. 5-7.

Ritzer, G. \& Jurgenson, N. (2010) 'Production, consumption, prosumption'. Journal of Consumer Culture, 10 (1) pp. 13-36.

Ross, A. (2013) 'In Search of the Lost Paycheck'. In Scholz, T. (ed.) (2013) Digital Labor: The Internet as Playground and Factory. London: Routledge.

Ross, J., Irani, L., Silberman, M., Zaldivar, A., \& Tomlinson, B. (2010) 'Who are the crowdworkers? Shifting demographics in mechanical turk'. Proceedings of the 28th of the international conference extended abstracts on Human factors in computing systems, ACM. pp. 2863-2872.

Saxtona, G.D., Ohb, O. \& Kishore, R. (2013) 'Rules of Crowdsourcing: Models, Issues, and Systems of Control'. Information Systems Management. Volume 30, Issue 1, 2013.

Schenk, E. and C. Guittard (2011) 'Towards a characterization of crowdsourcing practices', Journal of Innovation Economics (1), pp. 93-107.

Scholz, T. (2010) 'Facebook as Playground and Factory'. In Wittkower, D. E. (ed.) (2010) Facebook and Philosophy: What's on Your Mind? Volume 50. Open Court. 
Smythe, W. D. (2006) 'On the Audience Commodity and its Work'. In Durham, G. and Kellner D.M. (eds.) (2006) Media and cultural studies : keyworks. Blackwell Publishing Ltd.

Sotamaa, 0. (2007) 'Let Me Take You to The Movies: Productive Players, Commodification and Transformative Play'. Convergence: The International Journal of Research into New Media Technologies. November 2007 vol. 13 no. 4. pp. 383-401.

Spencer, D. A. (2009) The Political Economy of Work, Oxon: Routledge.

Terranova, T. (2013) 'Free Labor'. In Scholz, T. (ed.) Digital Labor: The Internet as Playground and Factory, London: Routledge.

Thomas, S. (2011) 9 examples of crowdsourcing, before 'crowdsourcing' existed. Memeburn: Tech-Savvy Insight and Analysis. [Online] Available at: http://memeburn.com/2011/09/9-examples-of-crowdsourcing-before\%E2\%80\%98crowdsourcing\%E2\%80\%99-existed/ [Accessed: 30 January, 2013].

von Ahn, L. (2010) Work and the Internet. [Blog] available at: http://vonahn.blogspot.co.uk/ [Accessed: 30 January, 2013].

von Ahn, L. (2009) 'Human Computation'. [Presentation] Computing Research that Changed the World: Reflections and Perspectives. Presentations from the March 25, 2009 Symposium. [Online] Available at: http://www.cra.org/ccc/ locsymposium_spfeat_vahn.php [Accessed: 30 January, 2013].

von Ahn, L., Maurer, B., McMillen, C., Abraham, D. \& Blum, M. (2008) 'reCAPTCHA: Human-Based Character Recognition via Web Security Measures'. Science. Volume 321 (5895), 12 September 2008. pp. 1465-1468.

von Ahn, L. \& Dabbish, L. (2008) 'General Techniques for Designing Games with a Purpose'. Communications of the ACM, August 2008. pp. 58-67.

von Ahn, L. (2006) 'Games with a Purpose'. Computer. Volume 39, Issue 6, June 2006, IEEE Computer Society. pp. 92 - 94.

Wang, P. (2006) A Marxian Analysis of World of Warcraft: Virtual Gaming Economies Reproducing Capitalistic Structures. [Online] Available at: [Accessed: 30 January, 2013].

Zott, C., Amit, R. \& Massa, L. (2011) 'The Business Model: Recent Developments and Future Research'. Journal of Management. July 2011 vol. 37 no. 4. pp. 10191042. 